\title{
The link between the brain volume derived index and the determinants of social performance
}

\author{
Keisuke Kokubun ${ }^{1,2}\left(\right.$ D $\cdot$ Yoshinori Yamakawa ${ }^{1,3,4,5,6} \cdot$ Kiyotaka Nemoto $^{7}(\mathbb{C}$
}

Accepted: 16 November 2021

(C) The Author(s) 2021, corrected publication 2022

\begin{abstract}
Motivation, defined as the energizing of behavior in pursuit of a goal, is a fundamental element of our interaction with the world and with each other. Furthermore, as it is known that cooperation leads to higher levels of performance than do individual conditions, empathic concern is also crucial to all forms of helping relationships. A growing number of studies indicate that motivation and empathy are associated not only with organizational performance and study achievements, but also with the human brain. However, to date, no definite neuroimaging-derived measures are available to measure motivation and empathy objectively. The current research evaluated the association of motivation and empathy with the whole brain using the gray-matter brain healthcare quotient (GM-BHQ), an MRI-based quotient. Participants were 47 healthy adults. All subjects underwent structural T1-weighted imaging. Motivation levels were evaluated using four motivation scales: Behavioral Activation System (BAS), Self-Monitoring Scale (SMS), Self-Control Scale (SCS), and Behavioral Inhibition System (BIS). Interaction levels, including empathic concern, were evaluated using four subscales of the Interpersonal Reactivity Index (IRI). It was found that the GM-BHQ was most significantly sensitive to the BAS scale $(p=0.002)$. Furthermore, the GM-BHQ was moderately sensitive to the SMS $(p=0.028)$ and subscales of the IRI $(p=0.044$ for Fantasy and $p=0.036$ for Empathic Concern). However, no significant association was found between the GM-BHQ and other variables (BIS and SCS). These results suggest that the GM-BHQ might reflect motivation and empathic concern.
\end{abstract}

Keywords Gray-matter brain healthcare quotient $\cdot$ Magnetic resonance imaging data $\cdot$ Interpersonal Reactivity Index (IRI) Self-Control Scale (SCS) · Self-Monitoring Scale (SMS) · Behavioral Inhibition System (BIS) · Behavioral Activation System (BAS) · Motivation

\section{Introduction}

Keisuke Kokubun

kokubun.keisuke.6x@kyoto-u.jp

Open Innovation Institute, Kyoto University, Kyoto, Japan

2 Smart-Aging Research Center, Tohoku University, Sendai, Japan

3 ImPACT Program of Council for Science, Technology and Innovation (Cabinet Office, Government of Japan), Tokyo, Japan

4 Institute of Innovative Research, Tokyo Institute of Technology, Tokyo, Japan

5 Office for Academic and Industrial Innovation, Kobe University, Kobe, Japan

6 Brain Impact, Kyoto, Japan

7 Department of Psychiatry, Faculty of Medicine, University of Tsukuba, Tsukuba, Japan
Motivation, defined as the energizing of behavior in pursuit of a goal, is a fundamental element of our interaction with the world and with each other (Smith et al., 2015). Previous studies have shown that motivation has a significant positive relationship with performance in academics (Covington, 2000), sports (Gillet et al., 2012), and research and development (Lai \& Chang, 2010), among others. In addition, those who have empathy for the other person are more likely to lead to higher performance through cooperation than individuals (Batson \& Ahmad, 2001; Faisal Ahammad et al., 2015; Flood and Klausner, 2018; Johnson \& Johnson, 1989; Reynolds \& Scott, 1999. Stratton et al., 2005). Moreover, there is also an increasing number of studies showing the relationship between motivation, empathy, and brain conditions (Barrós-Loscertales et al., 2006b; Ide et al., 2020; Li et al., 2014; Schulze et al., 2013; Yang et al., 
2016). However, previous studies have shown a relationship between the state of individual brain regions and individual psychological scales, but there was no comprehensive examination of the relationship between the overall state of the brain and motivation and empathy scales. Therefore, this study is the first to investigate the relationship between various motivation and empathy measures and the whole-brain gray matter volume (GMV) and makes a meaningful contribution to both psychological and brain research.

\section{Relationship between Motivation and Brain}

Motivational tendencies have been assessed using a variety of tools such as the Behavioral Activation System (BAS) and Self-Monitoring Scale (SMS). The BAS self-report questionnaire developed by Carver and White (Carver \& White, 1994) provides a measure of the individual's usual tendency to approach rewarding stimuli. In other words, the BAS is crucial for reward-related motivation (Levy \& Glimcher, 2012; Volkow et al., 2011) and is related to individuals' abilities to cope with uncertainties in their career development as well as individuals' career adaptability (Elliot \& Thrash, 2010). This system has also been found to correlate with positive feelings such as hope, joy and happiness (Carver \& White, 1994). The SMS is a scale that denotes the degree to which individuals are motivated to comply with social norms and modify their actions to meet normative expectations in social interactions (Snyder, 1974). Hence, individuals with relatively high self-monitoring are deeply concerned with their public appearance, and, consequently, they are willing to strictly control their expressive behavior (Gangestad \& Snyder, 2000). Indeed, it is found that self-monitoring is associated with achievement motivation (Kanani et al., 2017) as well as leadership, job performance and skills related to getting along with colleagues (Day et al., 2002).

Cooperation is another fundamental element of interaction with others. Indeed, Johnson and Johnson found that cooperation led to higher levels of performance than did individual conditions, indicating the positive potential of cooperation (Johnson \& Johnson, 1989). Other research indicates that cooperation is increased by empathy (Batson \& Ahmad, 2001), which is crucial to all forms of helping relationships (Reynolds \& Scott, 1999). In support, empathic concern measured through the Interpersonal Reactivity Index (IRI: Davis, 1980) was positively correlated with communication skills (Stratton et al., 2005). In the field of education, positive relationships between teacher empathy and student academic achievement have been found (Aspy, 1969; Robinson et al., 1981). Likewise, recent evidence in the medical field has shown that a higher level empathy is associated with higher levels of clinical competence (Casas et al., 2017; Hojat et al., 2011; Ogle et al., 2013). In the business field, motivation and empathy as a form of human resource development can be tailored into greater productivity and higher performance of businesspersons with the development of a strong organization and a positive work environment (Faisal Ahammad et al., 2015; Flood and Klausner, 2018). With individual national economies becoming ever more interdependent on the global economy, motivation and empathy have taken on an even greater importance.

In the field of neuroscience, previous studies have demonstrated that motivation measured with the BAS is positively associated with the ventral striatum GMV (Ide et al., 2020), mesolimbic and mesocortical dopamine projections (Clithero et al., 2011; Simon et al., 2010), and greater activity in the left frontal lobe (Balconi et al., 2012; HarmonJones et al., 2010). Other studies have indicated associations between Sensitivity to Reward scores (a BAS-related measure developed by Torrubia et al., 2001) and GMV in the dorsal striatum, prefrontal cortex, and inferior parietal lobule (Barrós-Loscertales et al., 2006b; Li et al., 2014). Motivation measured using the SMS is also reported to be correlated with GMV in the dorsal cingulate anterior cortex, dorsal lateral prefrontal cortex, and bilateral ventral striatum (Yang et al., 2016). Similarly, empathy with others has been suggested and shown to involve the anterior insula and mid cingulate cortex (Fan et al., 2011; Kurth et al., 2010; Singer \& Lamm, 2009; Tusche et al., 2016). Consistently, empathy measured using the IRI was positively correlated with GMV in the left anterior insula (Schulze et al., 2013). Another study found an influence of empathy on behavior through high-level activity in the left supramarginal gyrus (Yamaji et al., 2019). Considering this, GMV or neuroimaging-derived measures could be used to evaluate motivation or empathy.

However, there have been no studies showing the relationship between the state of the whole brain and motivation or empathy. Moreover, to date, no definite neuroimagingderived measures were available to assess motivation or empathy at the whole-brain level. Previously it was shown that the whole brain GMV is related to age (Nemoto et al., 2017), fatigue (Kokubun et al., 2018), curiosity (Kokubun et al., 2020), dietary balance (Kokubun \& Yamakawa, 2019), and lifestyle (Kokubun et al., 2021) using a neuroimaging-derived whole-brain measure, the "gray-matter brain healthcare quotient (GM-BHQ)" an international standard (H.861.1) approved by the International Telecommunication Union Telecommunication Standardization Sector (ITU-T). Here, GM-BHQ is an average of standardized gray matter measures for 116 brain regions based on the AAL atlas (Tzourio-Mazoyer et al., 2002). The advantage of the GMBHQ is that it makes it relatively easy to understand the state of the brain in terms of GMV. Moreover, GM-BHQ was more strongly correlated with cognitive function than its regional subscales including hippocampus-BHQ or 
parahippocampus-BHQ (Watanabe et al., 2021), indicating that the whole-brain GMV reflects cognitive function better than individual regional GMV. As the whole-brain GMV is influenced by one's personality, cognitive ability, and surrounding environment (Kokubun \& Yamakawa, 2019; Kokubun et al., 2018, 2020, 2021; Nemoto et al., 2017; Watanabe et al., 2021), it has been shown that motivation (Subramanian et al., 2020; Włodarska et al., 2019; Zhang et al., 2020) and empathy (Jami et al., 2021; Putrino et al., 2021) are also influenced by those factors. Therefore, it is reasonable to hypothesize that whole-brain GMV correlates with motivation and empathy.

\section{The Present Study}

This study reveals the relationship between GM-BHQ and the various motivation- and empathy-related psychological measures mentioned above. GM-BHQ is a measure that reflects whole brain GMV which is associated with various personal and environmental factors (Kokubun \& Yamakawa, 2019; Kokubun et al., 2018, 2020, 2021; Nemoto et al., 2017; Watanabe et al., 2021). Previous studies have clarified the relationship between individual brain regions and motivation- and empathy-related psychological indicators (Barrós-Loscertales et al., 2006b; Ide et al., 2020; Li et al., 2014; Schulze et al., 2013; Yang et al., 2016). Furthermore, it has been shown that motivation and empathy depend on various personal and environmental factors (Jami et al., 2021; Putrino et al., 2021; Subramanian et al., 2020; Włodarska et al., 2019; Zhang et al., 2020) as the brain condition did. Therefore, it was hypothesized that whole-brain GMV could also vary due to motivation and empathy levels.

\section{Methods}

\section{Participants}

Fifty-two healthy participants (37 females and 15 males) were recruited in Kyoto, Japan. Potential participants who had medical histories of neurological, psychiatric, or medical conditions that could affect the central nervous system were excluded from recruitment. After recruitment, the Self-Diagnostic Fatigue Check List (SDFCL; Kuratsune, 2014) was administered to screen for physical fatigue. The SDFCL scores of five participants were higher than the "cautious level" in terms of physical fatigue ( 8 points for men and 9 points for women), so they are excluded because our previous research indicates that the GM-BHQ is influenced by fatigue (Kokubun et al., 2018). Thus, the analysis included forty-seven participants (35 females and 12 males), aged 40-68 (mean (M) \pm standard deviation (SD): $49.1 \pm 6.8$ years). This study was approved by the ethics committee of Kyoto University (approval number 27-P-13) and performed in accordance with the guidelines and regulations of the institute. All participants gave written informed consent prior to participation, and participant anonymity has been preserved.

\section{Motivation and Empathy Scales}

In this study, the authors investigated the relationship between the GM-BHQ of healthy participants and the abovementioned motivation and interpersonal scales: BAS, SMS, and IRI. Additionally, to enrich our understanding of these associations, the authors employed two social psychological scales: the brief version of the Self-Control Scale (SCS: Tangney et al., 2004) and the Behavioral Inhibition System scale (BIS: Carver \& White, 1994). The authors chose these scales because they are scales of inhibitive or restrictive motivation, which provides a good contrast with the BAS and SMS scales.

Motivation scales are separated into two categories: One is the assessment of how an individual approaches reward stimuli while modifying their actions (BAS and SMS), and the other assesses how an individual withdraws or changes their emotions/behaviors to prevent them from emerging (BIS and SCS). Interpersonal scales (four subscales of the IRI: Perspective Taking (PT), Personal Distress (PD), Empathic Concern (EC), and Fantasy (F)) are for measuring empathy or belief in interactive situations with peers. As is discussed above, BIS and SCS may counteract effective or efficient behaviors. Therefore, the authors predict that they are negatively associated with or have no association with the GM-BHQ in contrast to the BAS, SMS, and IRI.

The authors employed four sets of motivation-scale questionnaires, BIS, BAS, SMS, and SCS, and one set of an empathy-scale questionnaire, IRI, to evaluate the motivation and empathy of participants. The summary of these questionnaires is shown in Table 1. The Japanese version of the Behavioral Inhibition/Activation Scales (BIS/BAS), originally developed by Carver and White (1994), comprises 20 questions (Takahashi et al., 2007). The BIS scale (7 items) measures sensitivity to avoidant behavior and fear of punishment while the BAS scale (13 items) measures anticipation of reward, motivation toward desired goals, and desire to approach novel situations with an expectation of reward.

The Self-Monitoring Scale (SMS), developed by Snyder (1974), measures people's ability and motivation to alter their behavior to accommodate social contexts. The original form of the SMS consists of 25 items with a true/false format. However, the present research employed a 5-point Likert scale as is similarly done in Briggs et al. (Briggs et al., 1980).

The Self-Control Scale (SCS) developed by Tangney et al. (Tangney et al. 2004) measures dispositional self-regulatory 
Table 1 Description of the scales used in this research

\begin{tabular}{|c|c|c|c|}
\hline Scale & $\begin{array}{l}\text { Number of items } \\
\text { comprising the } \\
\text { scale }\end{array}$ & Response scale & Sample item \\
\hline Behavioral Inhibition System (BIS) & 7 items & $\begin{array}{l}4 \text { points from } 1 \text { (strongly disagree) to } 4 \\
\text { (strongly agree) }\end{array}$ & Criticism or scolding hurts me quite a bit \\
\hline Behavioral Activation System (BAS) & 13 items & $\begin{array}{l}4 \text { points from } 1 \text { (strongly disagree) to } 4 \\
\text { (strongly agree) }\end{array}$ & $\begin{array}{l}\text { When I go after something, I don't hold } \\
\text { anything back }\end{array}$ \\
\hline Self-Monitoring Scale (SMS) & 25 items & $\begin{array}{l}5 \text { points from } 1 \text { (strongly disagree) to } 5 \\
\text { (strongly agree) }\end{array}$ & I'm not always the person I appear to be \\
\hline Self-Control Scale (SCS) & 13 items & $\begin{array}{l}5 \text { points from } 1 \text { (not at all like me) to } 5 \\
\text { (very much like me) }\end{array}$ & $\begin{array}{l}\text { People would say that I have iron self- } \\
\text { discipline }\end{array}$ \\
\hline $\begin{array}{l}\text { Perspective Taking (PT) subscale of } \\
\text { Interpersonal Reactivity Index (IRI) }\end{array}$ & 7 items & $\begin{array}{l}5 \text { points from }-2 \text { (does not describe me } \\
\text { well) to }+2 \text { (describes me very well) }\end{array}$ & $\begin{array}{l}\text { I try to look at everybody's side of a } \\
\text { disagreement before I make a decision }\end{array}$ \\
\hline $\begin{array}{l}\text { Personal Distress (PD) subscale of } \\
\text { Interpersonal Reactivity Index (IRI) }\end{array}$ & 7 items & $\begin{array}{l}5 \text { points from }-2 \text { (does not describe me } \\
\text { well) to }+2 \text { (describes me very well) }\end{array}$ & $\begin{array}{l}\text { In emergency situations, I feel apprehen- } \\
\text { sive and ill-at-ease }\end{array}$ \\
\hline $\begin{array}{l}\text { Empathic Concern (EC) subscale of } \\
\text { Interpersonal Reactivity Index (IRI) }\end{array}$ & 7 items & $\begin{array}{l}5 \text { points from }-2 \text { (does not describe me } \\
\text { well) to }+2 \text { (describes me very well) }\end{array}$ & $\begin{array}{l}\text { I often have tender, concerned feelings } \\
\text { for people less fortunate than me }\end{array}$ \\
\hline $\begin{array}{l}\text { Fantasy }(\mathrm{F}) \text { subscale of Interpersonal } \\
\text { Reactivity Index (IRI) }\end{array}$ & 7 items & $\begin{array}{l}5 \text { points from }-2 \text { (does not describe me } \\
\text { well) to }+2 \text { (describes me very well) }\end{array}$ & $\begin{array}{l}\text { I really get involved with the feelings of } \\
\text { the characters in a novel }\end{array}$ \\
\hline
\end{tabular}

behaviors. The current research employed the 13 -item brief version because the vast majority of researchers have used it.

The Interpersonal Reactivity Index (IRI; Davis, 1980), a widely used multi-dimensional measure of trait empathy, consists of four subscales: Perspective Taking (PT); Personal Distress (PD); Empathic Concern (EC); and Fantasy (F). PT measures the tendency to think from another's point of view; PD measures the response to difficult interpersonal situations of others; EC measures the sympathy for another's feelings; and F measures the use of imagination to experience the feelings and actions of characters in creative works. Each subscale contained seven items. They were measured on a five-point Likert scale.

The two motivational scores had good Cronbach's alpha internal consistencies (BAS: $\alpha=0.837$; SMS: $\alpha=0.837$ ). Further, the consistencies of most variable scores (IRIF: $\alpha=0.853$; IRI-PT: $\alpha=0.732$; IRI-PD: $\alpha=0.777$; SCS: $\alpha=0.804$ ) were over 0.7 which is a generally accepted level (Cortina, 1993; DeVellis, 2012). The consistencies of some variables, IRI-EC $(\alpha=0.646)$ and BIS $(\alpha=0.660)$, were relatively low, although still higher than 0.6 which is a looser acceptable level set by some researchers (Taber, 2018; Van Griethuijsen et al., 2015). However, the current research used them as they were because the values did not increase for either scale even when some items were deleted.

\section{MRI Data Acquisition}

Magnetic resonance imaging (MRI) data were obtained using $3 \mathrm{~T}$ scanners (Verio, Siemens Medical Solutions, Erlangen, Germany or MAGNETOM Prisma, Siemens, Munich, Germany) with a 32-channel head array coil. A three-dimensional T1-weighted magnetization-prepared rapid-acquisition gradient echo (MP-RAGE) pulse sequence produced a gapless series of sagittal sections. The parameters were as follows: repetition time (TR), $1900 \mathrm{~ms}$; echo time (TE), $2.52 \mathrm{~ms}$; inversion time (TI), $900 \mathrm{~ms}$; flip angle, $9^{\circ}$; matrix size, $256 \times 256$; field of view (FOV), $256 \mathrm{~mm}$; and slice thickness, $1 \mathrm{~mm}$.

\section{MRI Data Analysis}

The GM-BHQ was calculated according to our previous study (Nemoto et al., 2017). First, the authors segmented GM images from T1-weighted images using Statistical Parametric Mapping 12 (SPM12; Wellcome Trust Centre for Neuroimaging, London, UK) running on MATLAB R2015b (Mathworks Inc., Sherborn, MA, USA). Then the authors performed spatial normalization using an exponentiated Diffeomorphic Anatomical Registration Through Exponentiated Lie Algebra (DARTEL) algorithm (Ashburner, 2007). After spatial normalization through DARTEL, the authors performed modulation to preserve the GM volume. With the modulation, voxel value represents volume of participants. Then the authors did smoothing with an 8-mm full-width at half-maximum (FWHM) Gaussian kernel. The authors also calculated intracranial volume (ICV) for each subject by summing up grey matter volume, white matter volume, and cerebrospinal fluid volume. In order to adjust ICV, proportional GM images were generated by dividing preprocessed GM images by ICV across participants. Using these proportional GM images, mean and standard deviation (SD) images across participants were generated. From these images, the authors calculated the quotient images using the following 
formula: $100+15 \times$ (individual proportional GM - mean) / SD. Regional GM quotients were then extracted using an automated anatomical labeling (AAL) atlas (TzourioMazoyer et al., 2002) and averaged across regions to produce participant-specific GM-BHQ. Figure 1 shows the flowchart how GM-BHQ is calculated.

\section{Statistical Analysis}

In order to investigate the correlation between the GMBHQ and various variables, the authors employed hierarchical multiple regression analysis to examine differences in the degree of association between variables. The authors entered the control variables of age and sex in Step 1 and the main effects of sequential motivation-related or psychological variables individually in Step 2. In Step 3, the authors entered all the variables simultaneously using the step-wise variable selection method. This method is for simplifying statistical models, introducing the explanatory variables that have the most significant influence on specific dependent variables step by step until no newly added explanatory variables become statistically insignificant (Hocking, 1976). The authors added these respective variables to the models based on the hypothesis that motivational and other psychological variables are closely related to GM-BHQ after adjusting for age and sex. The significance level was determined at $p<0.05$. All statistical analyses were performed using IBM SPSS Statistics Version 26 (IBM Corp., Armonk, NY, USA).

\section{Results}

Descriptive statistics for subjects and correlation coefficients between psychological scales are shown in Table 2 . The GM-BHQ was correlated with age $(\mathrm{r}=-0.606, p<0.001)$ and $\operatorname{sex}(r=0.617, p<0.001)$ for a significance level of $p<0.05$. Therefore, the authors used these variables as control variables in the following hierarchical multiple regression analysis. The GM-BHQ was also correlated with IRI-F $(r=0.408$, $p<0.01)$ and BAS $(\mathrm{r}=0.496, p<0.001)$ for a significance level of $p<0.05$. Any of the correlation coefficient values is less than the critical value of 0.7 , indicating that there is no concern of multicollinearity even when they are input in a single multiple regression equation (Booth et al., 1994; Yu et al., 2015). However, the authors input the main variables one by one in this study based on the guidelines that one predictive variable can be studied for every ten (Hair et al., 2010; Peduzzi et al., 1996) or twenty (Schneider et al., 2010)
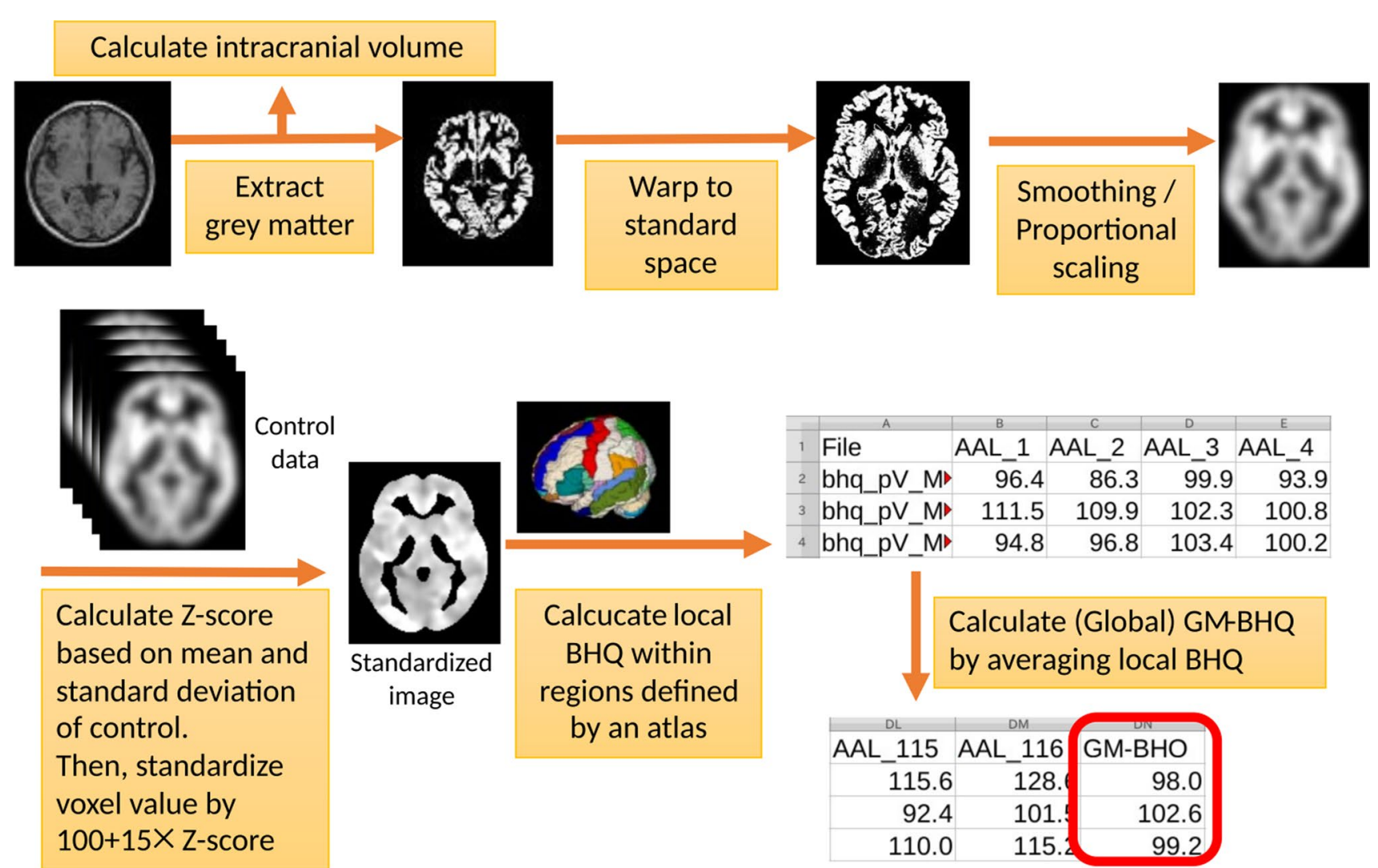
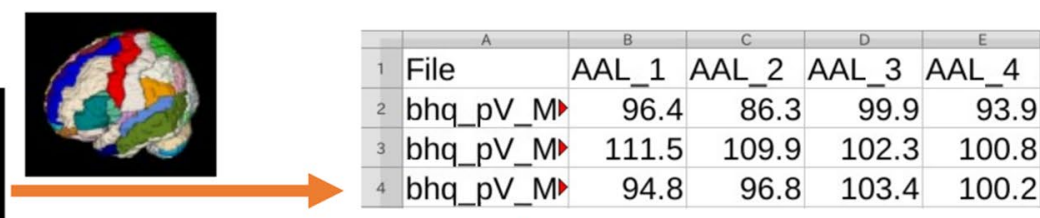

Calcucate local $\mathrm{BHQ}$ within regions defined by an atlas
Calculate (Global) GM-BHQ by averaging local $\mathrm{BHQ}$

\begin{tabular}{|r|r|r|}
\hline AAL_115 & AAL_116 & GM-BHO \\
\hline 115.6 & 128. & 98.0 \\
\hline 92.4 & 101. & 102.6 \\
\hline 110.0 & 115.2 & 99.2 \\
\hline
\end{tabular}

Fig. 1 Flowchart how GM-BHQ is calculated 


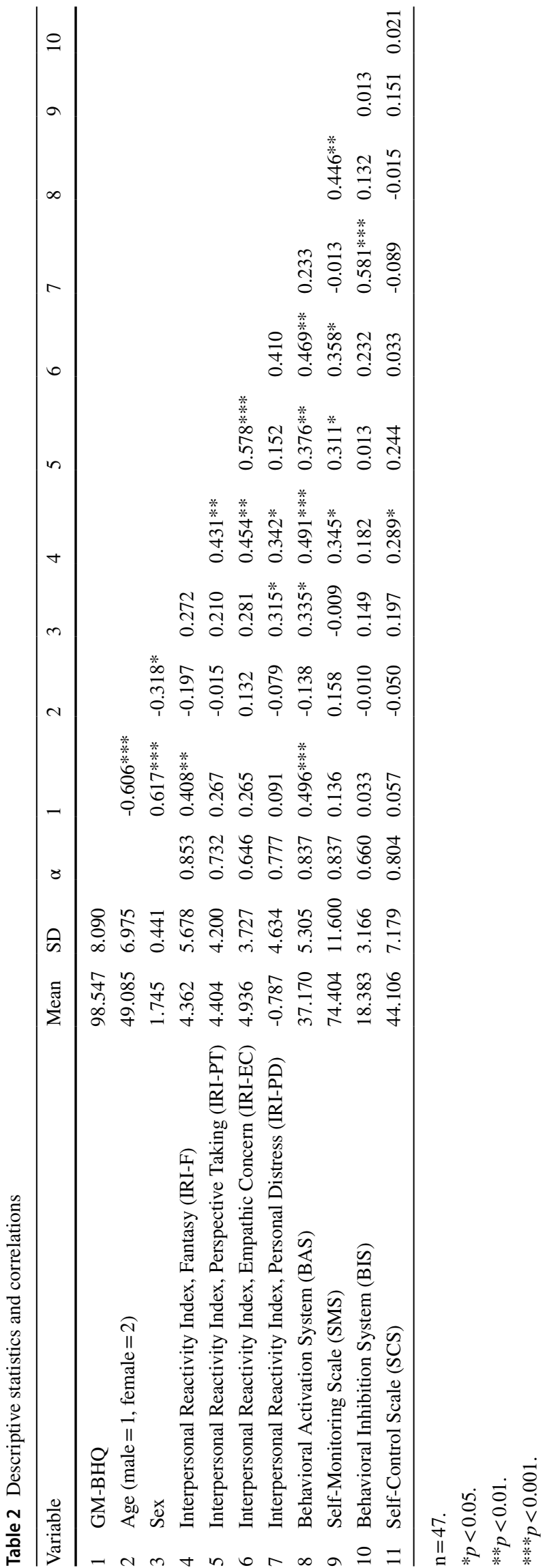

samples to avoid the problem of multicollinearity given the small number of samples.

Table 3 shows the results of hierarchical multiple regression analyses. In Step 1, both age $(\mathrm{R}=0.753, \beta=-0.485$, $p<0.001)$ and sex $(\mathrm{R}=0.753, \beta=0.472, p<0.001)$ were significant, revealing that GM-BHQ scores tended to be lower in male and elderly participants than in female and younger participants. In Step 2, in addition to age and sex, the main variables were added one by one. BAS $(\mathrm{R}=0.808, \beta=0.309$. $p=0.002), \mathrm{SMS}(\mathrm{R}=0.783, \beta=0.218$. $p=0.028)$, IRI-F $(\mathrm{R}=0.779, \beta=0.208 . p=0.044)$, and IRIEC $(\mathrm{R}=0.781, \beta=0.221 . p=0.036)$ were significantly associated with a higher GM-BHQ. In Step 3, only BAS was selected by the step-wise selection method as a variable significantly associated with higher GM-BHQ. Other variables, BIS $(\mathrm{R}=0.754, \beta=-0.043 . p=0.672)$, SCS $(\mathrm{R}=0.756, \beta=-0.061 . p=0.554)$, IRI-PT $(\mathrm{R}=0.771$, $\beta=0.169 . p=0.096)$, and IRI-PD $(\mathrm{R}=0.577, \beta=-0.104$. $p=0.324$ ), were not associated with GM-BHQ for a significance level of $p<0.05$. In support, with a Bonferroni correction (significance level divided by the number of independent tests), only one of the four results remained significant (BAS, $p=0.002<0.00625=0.05 / 8$ ). However, as there are significant correlations between BAS and other variables in Table 2, the authors may say SMS, IRI-F, and IRI-EC are at least indirectly associated with GM-BHQ through a correlation with BAS. Moreover, GMV without normalization (available upon request) did not correlate with any of these behavioral scales of the study because it does not represent the conditions of individual regions correctly. For reference, the scattered plots for correlation of GM-BHQ (controlled for differences in age and sex) with IRI-F, IRI-EC, BAS and SMS are shown in Figures. 2, 3, 4 and 5.

\section{Discussion}

In this research the authors explored the association of motivation and empathy with GMV. The authors found that the GM-BHQ was most significantly sensitive to BAS, which reflects anticipation of reward, motivation toward desired goals, and desire to approach novel situations with expectation of reward. Furthermore, the GM-BHQ was moderately sensitive to SMS and subscales of the IRI (Fantasy and Empathic Concern). However, no significant association was found between GM-BHQ and other variables (BIS and SCS). These results suggest that the GM-BHQ is associated with certain aspects of motivation and empathy evaluated by psychological tests.

Motivation, defined as the energizing of behavior in pursuit of a goal, is a fundamental element of our interaction with the world and with each other (Simpson \& Balsam, 2015). Empathy is another fundamental element since it is 


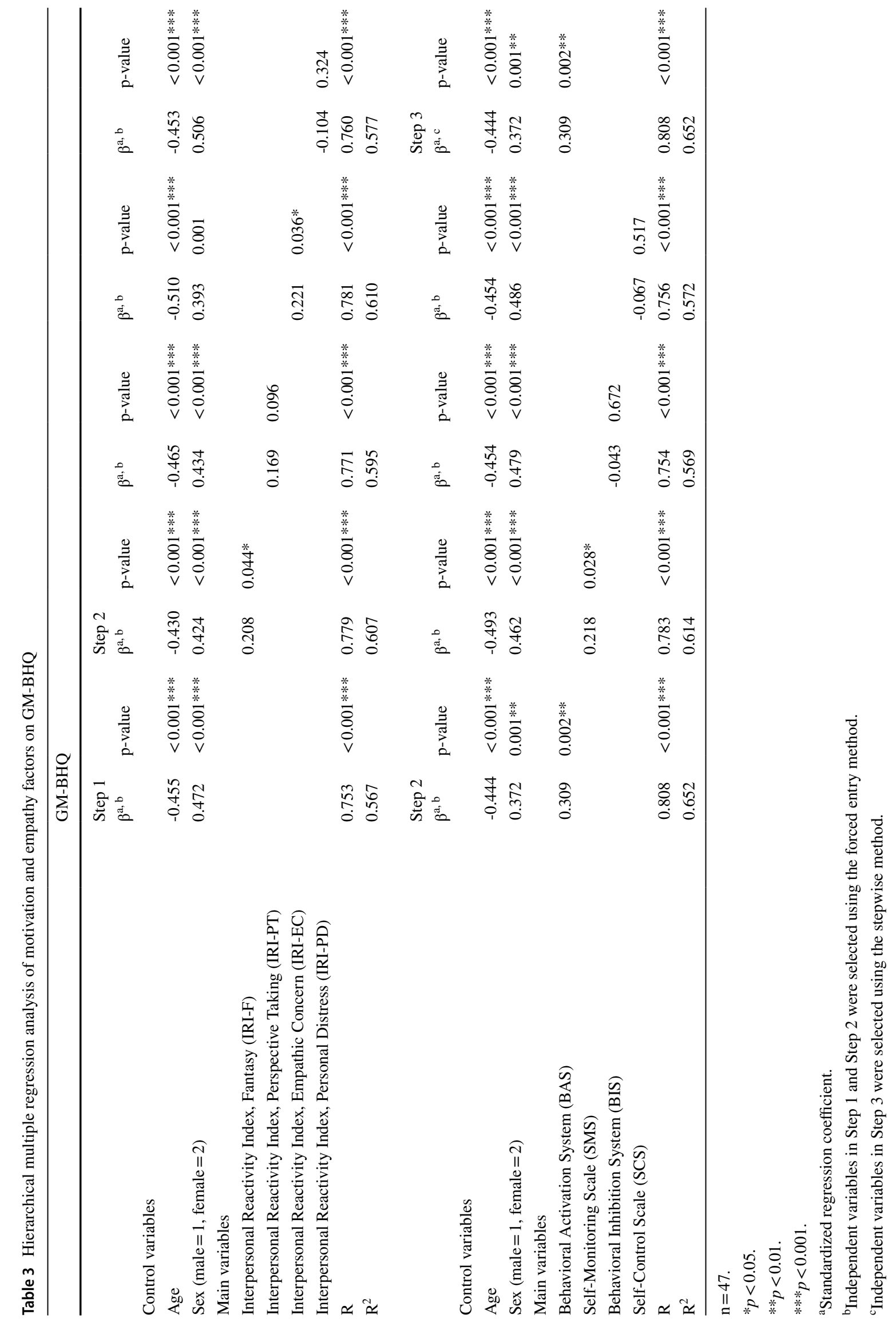




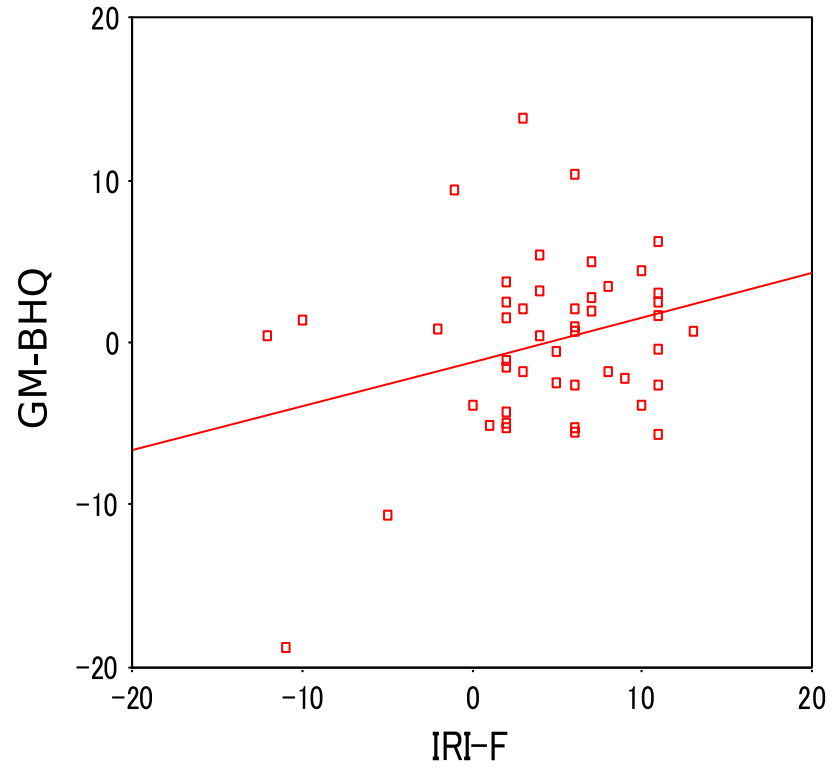

Fig. 2 Scatter plot of IRI-F and GM-BHQ GM-BHQ is controlled for differences in age and sex. The regression line is depicted

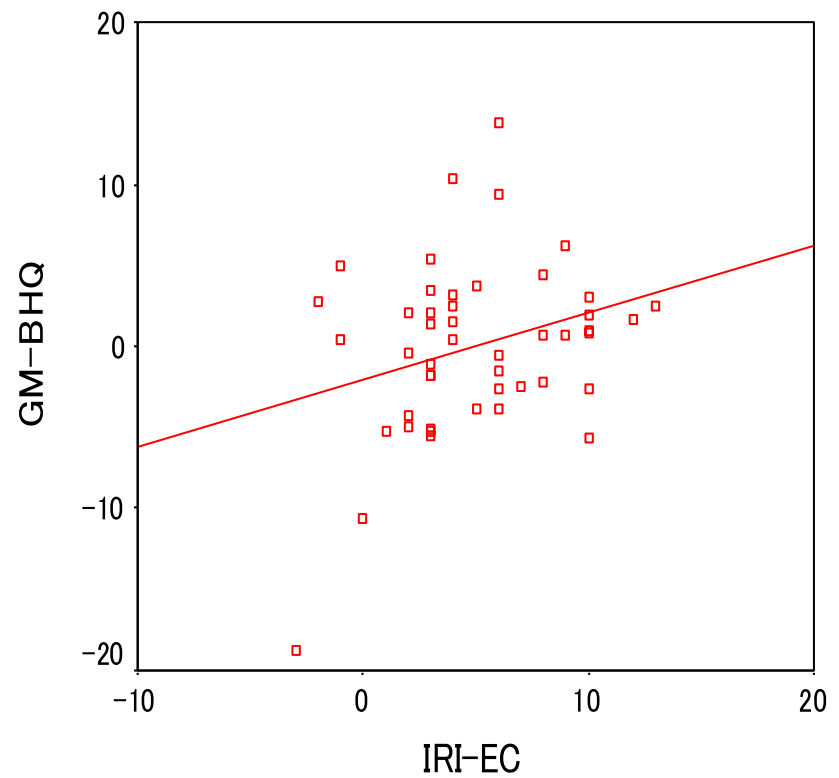

Fig. 3 Scatter plot of IRI-EC and GM-BHQ GM-BHQ is controlled for differences in age and sex. The regression line is depicted

well known that cooperation leads to higher levels of performance than do individual conditions. A growing number of studies indicate that motivation and empathy are associated not only with organizational performances or study achievements, but also with the human brain (Balconi et al., 2012; Barrós-Loscertales et al., 2006b; Clithero et al., 2011; Harmon-Jones et al., 2010; Li et al., 2014; Schulze et al., 2013; Simon et al., 2010; Yamaji et al., 2019; Yang et al., 2016). Consistent with previous findings, the authors found

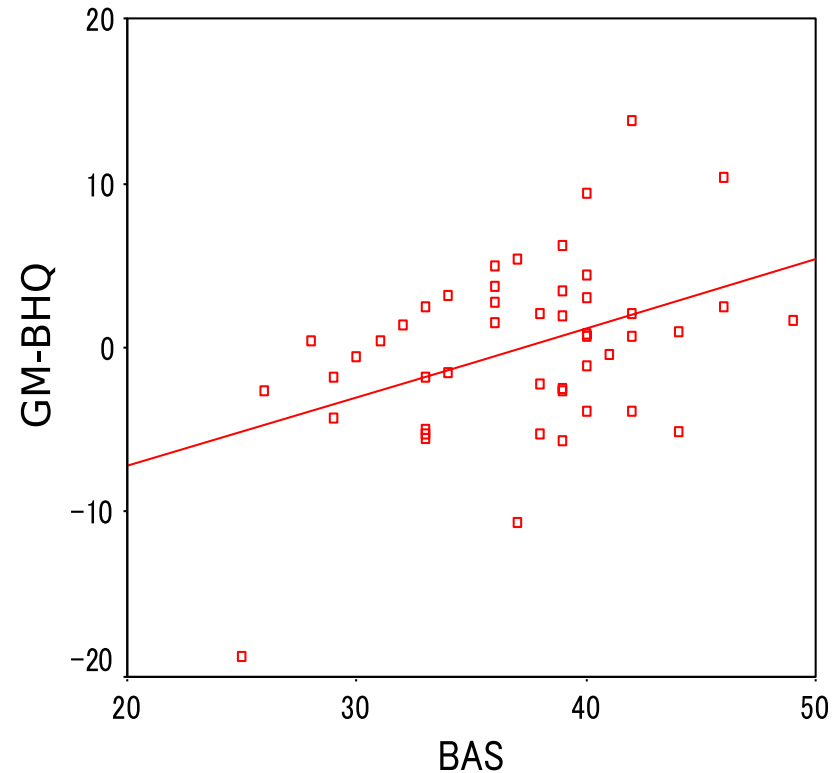

Fig. 4 Scatter plot of BAS and GM-BHQ GM-BHQ is controlled for differences in age and sex. The regression line is depicted

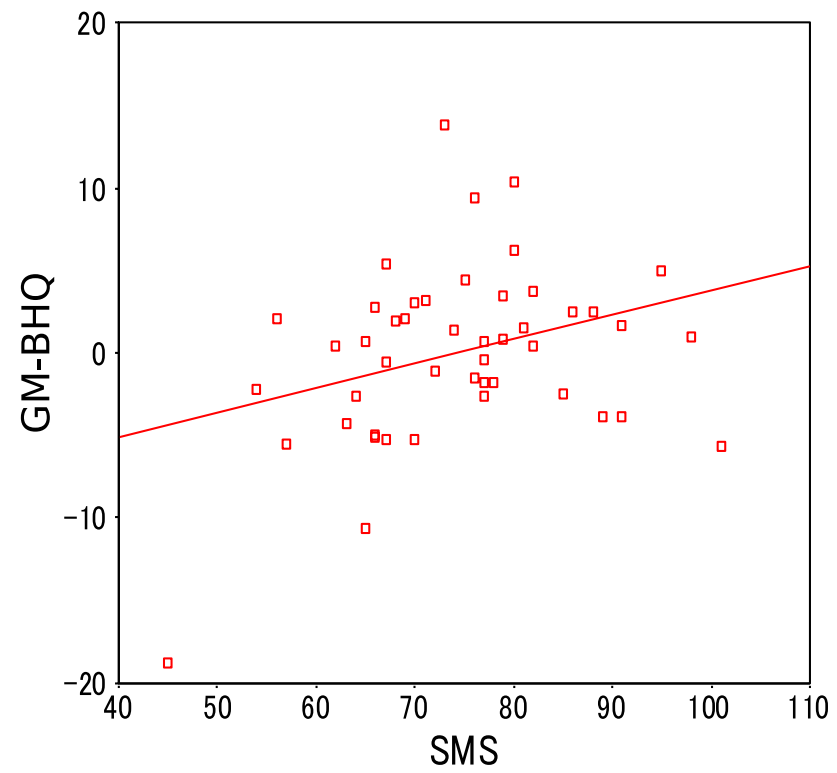

Fig. 5 Scatter plot of SMS and GM-BHQ GM-BHQ is controlled for differences in age and sex. The regression line is depicted

that GM-BHQ, a neuroimaging-derived measure, tends to be high in a person with high scores in BAS and SMS.

Previous research indicates that BAS may stimulate and sustain individuals' career exploration behavior ( $\mathrm{Li}$ et al., 2015), entrepreneurial actions and venture performance (Lerner et al., 2018). Other research found that the impact of performance-based financial incentives varied according to the abilities of the employees: while high-ability employees may change their level of effort to increase productivity, 
employees with lower abilities may not respond to such incentive schemes, but rather tend to remain at the same level of productivity (Faisal Ahammad et al., 2015). This indicates an association between reward responsiveness and ability. In support of such findings, in the field of neuroscience, it has been demonstrated that BAS is associated with mesolimbic and mesocortical dopamine projections (Clithero et al., 2011; Simon et al., 2010), which are recognized as crucial for reward-related motivation (Levy and Glimcher et al. 2012; Volkow et al., 2011). Moreover, according to other research, an association between reward sensitivity and GMV is seen in the ventral striatum, the dorsal striatum, prefrontal cortex, and inferior parietal lobule (BarrósLoscertales et al., 2006b; Ide et al., 2020; Li et al., 2014). Previous studies have shown that there is a negative correlation between reward sensitivity and GMV in some regions (Ide et al., 2020). However, the current study shows that the positive or negative correlation between GMV and reward sensitivity in individual regions is shown as a positive correlation when viewed throughout the brain.

However, the authors may have to carefully observe research with contradicting results before the authors develop a more definite understanding of BAS. For instance, previous research has shown the experience of anger to be highly correlated to BAS (Harmon-Jones \& Peterson, 2008). BAS has also been linked to unhealthy behaviors related to safety, tobacco and other drug use, alcohol consumption, and sexual practices (Voigt et al., 1994). Results from a neuroscience study corroborate these findings by revealing consistent significant relationships between anger self-reported with the BAS and left frontal cortical activation (Watson et al., 2016). Therefore, simply maintaining a high BAS is not enough; our behavior must at the same time be appropriately controlled in order for us to live successfully within this society.

In this sense, one promising solution may be individuals' abilities to accurately assess social situations and to respond appropriately to various situations; this is known as self-monitoring (Snyder, 1974). Studies have shown significant associations between SMS and work-related outcomes associated with job performance, advancement ability (Day et al., 2002; Kilduff \& Day, 1994; Mehra et al., 2001), job motivation, and employee well-being (Day \& Schleicher, 2006). Research also indicates that high self-monitors are more likely to emerge as leaders (Ellis, 1988; Zaccaro et al., 1991), receive more promotions (Kilduff \& Day, 1994; O'Neill \& O'Reilly, 2011) and resolve conflicts through collaboration and compromise (Baron, 1989) because they are more skilled at social interactions (Furnham \& Capon, 1983).

However, simply maintaining high BAS and SMS simultaneously may not be sufficient. It is reported that SMS correlates with the three socially malevolent personality traits: narcissism, Machiavellianism, and psychopathy (Kowalski et al., 2018). As we do not live alone, but together with many people in this society, we must acquire skills to cooperate with peers successfully. For that reason, people may have to consider others more often. Indeed, social psychological approaches suggest empathy as one of the most important motivations for altruistic behavior (Pavey et al., 2012). In line with this, previous research indicates that "Empathic Concern", a subscale of the Interpersonal Reactivity Index (IRI), predicts altruistic behaviors and in turn fosters mature prosocial moral reasoning (Edele et al., 2013; Paciello et al., 2013). Other research has also elucidated that this scale is positively associated with social competence, and in turn with academic performance (Zorza et al., 2013), but negatively associated with aggressive behavior of schoolage adolescents (Batanova \& Loukas, 2011). In the area of neuroscience, Empathic Concern was positively correlated with left anterior insula GMV (Schulze et al., 2013), and "Fantasy", another subscale of the IRI, was positively related with GMV in the right dorsolateral prefrontal cortex (Banissy et al., 2012). Conversely, it is found that "Personal Distress", one of the four subscales of the IRI, may enhance moral disengagement mechanisms that may facilitate selfcentered behaviors (Edele et al., 2013). The good news is that among these IRI subscales, the current research shows that Empathic Concern and Fantasy are positively correlated with the GM-BHQ while Personal Distress is not. The reason the fourth subscale, "Perspective Taking", was not significantly correlated with the GM-BHQ may be a difference in the purpose of the scales: Perspective Taking measures the cognitive aspects of empathy in contrast with Empathic Concern, which measures the emotional aspects of empathy (Ritter et al., 2011).

In contrast, the behavioral inhibition system (BIS), which is a sensitivity to negative stimuli inhibiting behavior to protect individuals from negative or painful outcomes (Carver \& White, 1994), was not significantly correlated with the GM-BHQ, contradicting previous research which found positive correlations between a BIS-related measure and GMV in the bilateral amygdala and the hippocampal formation (Barrós-Loscertales et al., 2006a) and negative correlations between the BIS and GMV in the ventral striatum, the ventral caudate and bilateral putamen/pallidum, hypothalamus, and right anterior insula (Ide et al., 2020). This difference indicates that the BIS may be associated with regional GMV positively and negatively, but not with whole-brain GMV by canceling these correlations with each other. Likewise, the Self-Control Scale (SCS), which measures the inhibition of some undesirable behaviors and has to do with human morals or discipline (Tangney et al. 2004), was not significantly associated with the GM-BHQ. These differences are essential to understanding the features of the GM-BHQ more accurately. The ability to proceed with certain behavior 
(BAS) or to adjust certain behaviors (SMS) may be easily attainable with a healthy brain, but the ability to withdraw (BIS) or inhibit behaviors (SCS) may not be as easily attainable as they require judgments based on one's experiences.

Our results are in line with the findings of previous research, and at the same time offer new knowledge that the condition of the whole brain, as measured by the GM-BHQ, is positively related to BAS, SMS, and subscales of the IRI (Fantasy and Empathic Concern), but not to BIS and SCS in healthy people. These findings indicate that people who have good whole-brain health, as measured by the GM-BHQ, tend to have high motivation in areas including reward responsiveness and self-monitoring abilities together with interpersonal reactivity without becoming anxious or negative.

Many studies have elucidated the roles of specific brain regions by investigating their individual relationships with scores of psychological tests. However, our research has found a novel association between the brain volume derived index and several psychological scales. This finding provides a bridge for future research into clarifying what role the condition of the brain plays in regards to individual performance within society, in line with previous studies which have shown links between brain age and mortality (Cole et al., 2018) or positive-negative modes and brain connectivity (Smith et al., 2015).

There are three limitations to this study. First, the small sample size may influence the generalizability of our results. Second, measures of general cognitive performance to control for possible confounding effects of intelligence may have improved the reliability of the regression, although the authors confirmed no significant correlation between educational background and GM-BHQ (available upon request). Third, other motivation and social psychological scales unused in this research may have improved the interpretability of the data. Further studies are needed to explore the relationship between the GM-BHQ and more varied psychological states, as measured through questionnaires, using larger sample sizes to clarify in greater detail the mechanisms which connect them. Confirming the validity of this study, which shows the relationship between motivation and empathy and the brain, can be expected to lead to the creation of new services using a simple brain measurement scale such as GM-BHQ in the future.

Author Contributions K.K. did formal analysis and writing original draft; Y.Y. and K.N. did conceptualization; Y.Y. did data curation, funding acquisition, investigation, administration and supervision; K.N. did methodology development, writing review and editing. All authors reviewed the final manuscript.

Funding This work was funded by ImPACT Program of Council for Science, Technology and Innovation (Cabinet Office,
Government of Japan) and supported by JSPS KAKENHI (Grant Number JP18K18164; JP17H06151).

Data Availability The datasets generated during the current study are available from the corresponding author on reasonable request.

\section{Declarations}

Ethical Approval The studies involving human participants were reviewed and approved by the Ethics Committees of Kyoto University (approval number 27-P-13).

Informed Consent The patients/participants provided their written informed consent to participate in this study.

Conflict of Interest There is no conflict interest.

Open Access This article is licensed under a Creative Commons Attribution 4.0 International License, which permits use, sharing, adaptation, distribution and reproduction in any medium or format, as long as you give appropriate credit to the original author(s) and the source, provide a link to the Creative Commons licence, and indicate if changes were made. The images or other third party material in this article are included in the article's Creative Commons licence, unless indicated otherwise in a credit line to the material. If material is not included in the article's Creative Commons licence and your intended use is not permitted by statutory regulation or exceeds the permitted use, you will need to obtain permission directly from the copyright holder. To view a copy of this licence, visit http://creativecommons.org/licenses/by/4.0/.

\section{References}

Ashburner, J. (2007). A fast diffeomorphic image registration algorithm. NeuroImage, 38, 95-113. https://doi.org/10.1016/j.neuro image.2007.07.007

Aspy, D. N. (1969). The effect of teacher-offered conditions of empathy, positive regard, and congruence upon student achievement. Florida Journal of Educational Research, 11, 39-48.

Balconi, M., Falbo, L., \& Conte, V. A. (2012). BIS and BAS correlates with psychophysiological and cortical response systems during aversive and appetitive emotional stimuli processing. Motivation and Emotion, 36, 218-231. https://doi.org/10.1007/ s11031-011-9244-7

Banissy, M. J., Kanai, R., Walsh, V., \& Rees, G. (2012). Inter-individual differences in empathy are reflected in human brain structure. NeuroImage, 62, 2034-2039. https://doi.org/10.1016/j.neuro image.2012.05.081

Baron, R. A. (1989). Personality and organizational conflict: Effects of the Type A behavior pattern and self-monitoring. Organizational Behavior and Human Decision Processes, 44, 281-296. https:// doi.org/10.1016/0749-5978(89)90028-9

Barrós-Loscertales, A., Meseguer, V., Sanjuán, A., Belloch, V., Parcet, M. A., Torrubia, R., \& Ávila, C. (2006a). Behavioral inhibition system activity is associated with increased amygdala and hippocampal gray matter volume: A voxel-based morphometry study. NeuroImage, 33, 1011-1015. https://doi.org/10.1016/j.neuro image.2006.07.025

Barrós-Loscertales, A., Meseguer, V., Sanjuán, A., Belloch, V., Parcet, M. A., Torrubia, R., \& Ávila, C. (2006b). Striatum gray matter reduction in males with an overactive behavioral activation system. European Journal of Neuroscience, 24, 2071-2074. https:// doi.org/10.1111/j.1460-9568.2006.05084.x 
Batanova, M. D., \& Loukas, A. (2011). Social anxiety and aggression in early adolescents: Examining the moderating roles of empathic concern and perspective taking. Journal of Youth and Adolescence, 40, 1534-1543. https://doi.org/10.1007/s10964-011-9634-x

Batson, C. D., \& Ahmad, N. (2001). Empathy-induced altruism in a prisoner's dilemma II: What if the target of empathy has defected? European Journal of Social Psychology, 31, 25-36. https://doi. org/10.1002/ejsp.26

Booth, G. D., Niccolucci, M. J., \& Schuster, E. G. (1994). Identifying Proxy Sets in Multiple Linear Regression: An Aid to Better Coefficient Interpretation. Ogden: US Department of Agriculture Forest Service.

Briggs, S. R., Cheek, J. M., \& Buss, A. H. (1980). An analysis of the self-monitoring scale. Journal of Personality and Social Psychology, 38, 679-686.

Carver, C. S., \& White, T. L. (1994). Behavioral inhibition, behavioral activation, and affective responses to impending reward and punishment: The BIS/BAS scales. Journal of Personality and Social Psychology, 67, 319-333.

Casas, R. S., Xuan, Z., Jackson, A. H., Stanfield, L. E., Harvey, N. C., \& Chen, D. C. (2017). Associations of medical student empathy with clinical competence. Patient Education and Counseling, 100, 742-747. https://doi.org/10.1016/j.pec.2016.11.006

Clithero, J. A., Reeck, C., Carter, R. M., Smith, D. V., \& Huettel, S. A. (2011). Nucleus accumbens mediates relative motivation for rewards in the absence of choice. Frontiers in Human Neuroscience, 5, 87. https://doi.org/10.3389/fnhum.2011.00087

Cole, J. H., Ritchie, S. J., Bastin, M. E., Hernández, M. V., Maniega, S. M., Royle, N., Corley, J., Pattie, A., Harris, S. E., Zhang, Q., Wray, N. R., Redmond, P., Marioni, R. E., Starr, J. M., Cox, S. R., Wardlaw, J. M., Sharp, D. J., \& Deary, I. J. (2018). Brain age predicts mortality. Molecular Psychiatry, 23, 1385-1392. https:// doi.org/10.1038/mp.2017.62

Cortina, J. M. (1993). What is coefficient alpha? An examination of theory and applications. Journal of Applied Psychology, 78, 98-104. https://doi.org/10.1037/0021-9010.78.1.98

Covington, M. V. (2000). Goal theory, motivation, and school achievement: An integrative review. Annual Review of Psychology, 51, 171-200. https://doi.org/10.1146/annurev.psych.51.1.171

Davis, M. H. (1980). A multidimensional approach to individual differences in empathy. Journal Supplement Abstract Service Catalog of Selected Documents in Psychology, 10, 85.

Day, D. V., \& Schleicher, D. J. (2006). Self-monitoring at work: A motive-based perspective. Journal of Personality, 74, 685-714. https://doi.org/10.1111/j.1467-6494.2006.00389.x

Day, D. V., Shleicher, D. J., Unckless, A. L., \& Hiller, N. J. (2002). Self-monitoring personality at work: A meta-analytic investigation of construct validity. Journal of Applied Psychology, 87, 390-401.

DeVellis, R. F. (2012). Scale Development: Theory and Applications. Sage publications.

Edele, A., Dziobek, I., \& Keller, M. (2013). Explaining altruistic sharing in the dictator game: The role of affective empathy, cognitive empathy, and justice sensitivity. Learning and Individual Differences, 24, 96-102. https://doi.org/10.1016/j.lindif.2012.12.020

Elliot, A. J., \& Thrash, T. M. (2010). Approach and avoidance temperament as basic dimensions of personality. Journal of Personality, 78, 865-906.

Ellis, R. J. (1988). Self-monitoring and leader emergence in groups. Personality and Social Psychology Bulletin, 14, 681-693.

Faisal Ahammad, M., Mook Lee, S., Malul, M., \& Shoham, A. (2015). Behavioral ambidexterity: The impact of incentive schemes on productivity, motivation, and performance of employees in commercial banks. Human Resource Management, 54, S45-S62. https://doi.org/10.1002/hrm.21668

Fan, Y., Duncan, N. W., de Greck, M., \& Northoff, G. (2011). Is there a core neural network in empathy? An fMRI based quantitative meta-analysis. Neuroscience \& Biobehavioral Reviews, 35, $903-$ 911. https://doi.org/10.1016/j.neubiorev.2010.10.009

Flood, F., \& Klausner, M. (2018). High-performance work teams and organizations. In A. Farazmand (Ed.), Global encyclopedia of public administration, public policy, and governance (pp. 1-6). Springer International Publishing AG.

Furnham, A., \& Capon, M. (1983). Social skills and self-monitoring processes. Personality and Individual Differences, 4, 171-178. https://doi.org/10.1016/0191-8869(83)90017-X

Gangestad, S. W., \& Snyder, M. (2000). Self-monitoring: Appraisal and reappraisal. Psychological Bulletin, 126, 530-555. https://doi.org/ 10.1037/0033-2909.126.4.530

Gillet, N., Berjot, S., Vallerand, R. J., Amoura, S., \& Rosnet, E. (2012). Examining the motivation-performance relationship in competitive sport: A cluster-analytic approach. International Journal of Sport Psychology, 43, 79-102.

Hair, J. F., Black, W. C., Babin, B. J., \& Anderson, R. E. (2010). Multivariate data analysis (7th ed.). Prentice Hall.

Harmon-Jones, E., \& Peterson, C. K. (2008). Effect of trait and state approach motivation on aggressive inclinations. Journal of Research in Personality, 42, 1381-1385. https://doi.org/10.1016/j. jrp.2008.05.001

Harmon-Jones, E., Gable, P. A., \& Peterson, C. K. (2010). The role of asymmetric frontal cortical activity in emotion-related phenomena: A review and update. Biological Psychology, 84, 451-462. https://doi.org/10.1016/j.biopsycho.2009.08.010

Hocking, R. R. (1976). A Biometrics invited paper. The analysis and selection of variables in linear regression. Biometrics, 32, 1-49. https://doi.org/10.2307/2529336

Hojat, M., Louis, D. Z., Markham, F. W., Wender, R., Rabinowitz, C., \& Gonnella, J. S. (2011). Physicians' empathy and clinical outcomes for diabetic patients. Academic Medicine, 86, 359-364. https://doi.org/10.1097/ACM.0b013e3182086fe1

Ide, J. S., Li, H. T., Chen, Y., Le, T. M., Li, C. S., Zhornitsky, S., \& Li, C. S. R. (2020). Gray matter volumetric correlates of behavioral activation and inhibition system traits in children: An exploratory voxel-based morphometry study of the ABCD project data. NeuroImage, 220, 117085. https://doi.org/10.1016/j.neuroimage. 2020.117085

Jami, P. Y., Mansouri, B., \& Thoma, S. J. (2021). Age, gender, and educational level predict emotional but not cognitive empathy in farsi-speaking iranians. Current Psychology, 40, 534-544. https:// doi.org/10.1007/s12144-018-9967-7

Johnson, D., \& Johnson, R. (1989). Cooperation and competition: theory and research. Edina, MN: Interaction Book.

Kanani, Z., Adibsereshki, N., \& Haghgoo, H. A. (2017). The effect of self-monitoring training on the achievement motivation of students with dyslexia. Journal of Research in Childhood Education, $31,430-439$.

Kilduff, M., \& Day, D. V. (1994). Do chameleons get ahead? The effects of self-monitoring on managerial careers. Academy of Management Journal, 37, 1047-1060. https://doi.org/10.5465/ 256612

Kokubun, K., Nemoto, K., Oka, H., Fukuda, H., Yamakawa, Y., \& Watanabe, Y. (2018). Association of fatigue and stress with gray matter volume. Frontiers in Behavioral Neuroscience, 12, 154. https://doi.org/10.3389/fnbeh.2018.00154

Kokubun, K., Pineda, J. C. D., \& Yamakawa, Y. (2021). Unhealthy lifestyles and brain condition: Examining the relations of BMI, living alone, alcohol intake, short sleep, smoking, and lack of exercise with gray matter volume. PLOS ONE, 16, e0255285. https://doi. org/10.1371/journal.pone.0255285

Kokubun, K., \& Yamakawa, Y. (2019). Association between food patterns and gray matter volume. Frontiers in Human Neuroscience, 13, 384. https://doi.org/10.3389/fnhum.2019.00384 
Kokubun, K., Yamakawa, Y., \& Hiraki, K. (2020). Association between Behavioral Ambidexterity and Brain Health. Brain Sciences, 10, 137. https://doi.org/10.3390/brainsci10030137

Kowalski, C. M., Rogoza, R., Vernon, P. A., \& Schermer, J. A. (2018). The Dark Triad and the self-presentation variables of socially desirable responding and self-monitoring. Personality and Individual Differences, 120, 234-237. https://doi.org/10.1016/j.paid. 2017.09.007

Kuratsune, H. (2014). Mansei hirō shōkōgun ni taisuru chiryō-hō no kakuritsu (Establishment of treatment for chronic fatigue syndrome) in Ministry of Education, Culture, Sports, Science and Technology (Ed.), Seikatsu-sha nīzu taiō kenkyū: Hirō oyobi hirō-kan no bunshi shinkei mekanizumu to sono bōgyo ni kansuru kenkyū hirō no bōshi (Research on consumer needs: Research on molecular and neural mechanisms of fatigue and its prevention (pp. 305-361). Tokyo: Ministry of Education, Culture, Sports, Science and Technology (in Japanese).

Kurth, F., Zilles, K., Fox, P. T., Laird, A. R., \& Eickhoff, S. B. (2010). A link between the systems: Functional differentiation and integration within the human insula revealed by meta-analysis. Brain Structure and Function, 214, 519-534. https://doi.org/10.1007/ s00429-010-0255-Z

Lai, W. H., \& Chang, P. L. (2010). Corporate motivation and performance in R\&D alliances. Journal of Business Research, 63, 490-496. https://doi.org/10.1016/j.jbusres.2009.04.007

Lerner, D. A., Hatak, I., \& Rauch, A. (2018). Deep roots? Behavioral inhibition and behavioral activation system (BIS/BAS) sensitivity and entrepreneurship. Journal of Business Venturing Insights, 9, 107-115. https://doi.org/10.1016/j.jbvi.2018.02.005

Levy, D. J., \& Glimcher, P. W. (2012). The root of all value: A neural common currency for choice. Current Opinion in Neurobiology, 22, 1027-1038. https://doi.org/10.1016/j.conb.2012.06.001

Li, Y., Qiao, L., Sun, J., Wei, D., Li, W., Qiu, J., Zhang, Q., \& Shi, H. (2014). Gender-specific neuroanatomical basis of behavioral inhibition/approach systems (BIS/BAS) in a large sample of young adults: A voxel-based morphometric investigation. Behavioural Brain Research, 274, 400-408. https://doi.org/10.1016/j.bbr.2014. 08.041

Li, Y., Guan, Y., Wang, F., Zhou, X., Guo, K., Jiang, P., Mo, Z., Li, Y., \& Fang, Z. (2015). Big-five personality and BIS/BAS traits as predictors of career exploration: The mediation role of career adaptability. Journal of Vocational Behavior, 89, 39-45. https:// doi.org/10.1016/j.jvb.2015.04.006

Mehra, A., Kilduff, M., \& Brass, D. J. (2001). The social networks of high and low self-monitors: Implications for workplace performance. Administrative Science Quarterly, 46, 121-146. https:// doi.org/10.2307/2667127

Nemoto, K., Oka, H., Fukuda, H., \& Yamakawa, Y. (2017). MRIbased Brain Healthcare Quotients: A bridge between neural and behavioral analyses for keeping the brain healthy. PLOS ONE, 12, e0187137. https://doi.org/10.1371/journal.pone.0187137

Ogle, J., Bushnell, J. A., \& Caputi, P. (2013). Empathy is related to clinical competence in medical care. Medical Education, 47, 824-831. https://doi.org/10.1111/medu.12232

O'Neill, O. A., \& O'Reilly, C. A., III. (2011). Reducing the backlash effect: Self-monitoring and women's promotions. Journal of Occupational and Organizational Psychology, 84, 825-832. https://doi.org/10.1111/j.2044-8325.2010.02008.x

Paciello, M., Fida, R., Cerniglia, L., Tramontano, C., \& Cole, E. (2013). High cost helping scenario: The role of empathy, prosocial reasoning and moral disengagement on helping behavior. Personality and Individual Differences, 55, 3-7. https://doi.org/10. 1016/j.paid.2012.11.004

Pavey, L., Greitemeyer, T., \& Sparks, P. (2012). "I help because I want to, not because you tell me to" empathy increases autonomously motivated helping. Personality and Social Psychology Bulletin, 38, 681-689. https://doi.org/10.1177/0146167211435940

Peduzzi, P., Concato, J., Kemper, E., Holford, T. R., \& Feinstein, A. R. (1996). A simulation study of the number of events per variable in logistic regression analysis. Journal of Clinical Epidemiology, 49, 1373-1379. https://doi.org/10.1016/S0895-4356(96)00236-3

Putrino, N., Tabullo, Á., Mesurado, B., \& de Minzi, M. C. R. (2021). Are there differences in health professionals' empathy due to academic and clinical experience? Current Psychology, 40, 647-654. https://doi.org/10.1007/s12144-018-9980-x

Reynolds, W. J., \& Scott, B. (1999). Empathy: A crucial component of the helping relationship. Journal of Psychiatric and Mental Health Nursing, 6, 363-370. https://doi.org/10.1046/j.1365-2850. 1999.00228.x

Ritter, K., Dziobek, I., Preißler, S., Rüter, A., Vater, A., Fydrich, T., Lammers, C. H., Heekeren, H. R., \& Roepke, S. (2011). Lack of empathy in patients with narcissistic personality disorder. Psychiatry Research, 187, 241-247. https://doi.org/10.1016/j.psych res.2010.09.013

Robinson, E. H., Wilson, E. S., \& Robinson, S. L. (1981). The effects of perceived levels of warmth and empathy on student achievement. Reading Improvement, 18, 313-318.

Schneider, A., Hommel, G., \& Blettner, M. (2010). Linear regression analysis: Part 14 of a series on evaluation of scientific publications. Deutsches Ärzteblatt International, 107, 776-782. https:// doi.org/10.3238/arztebl.2010.0776

Schulze, L., Dziobek, I., Vater, A., Heekeren, H. R., Bajbouj, M., Renneberg, B., Heuser, I., \& Roepke, S. (2013). Gray matter abnormalities in patients with narcissistic personality disorder. Journal of Psychiatric Research, 47, 1363-1369. https://doi.org/10.1016/j. jpsychires.2013.05.017

Simon, J. J., Walther, S., Fiebach, C. J., Friederich, H. C., Stippich, C., Weisbrod, M., \& Kaiser, S. (2010). Neural reward processing is modulated by approach-and avoidance-related personality traits. NeuroImage, 49, 1868-1874. https://doi.org/10.1016/j.neuro image.2009.09.016

Simpson, E. H., \& Balsam, P. D. (2015). The behavioral neuroscience of motivation: An overview of concepts, measures, and translational applications. In E. Simpson \& P. Balsam (Eds). Behavioral neuroscience of motivation. Current topics in behavioral neurosciences, 27, 1-12. https://doi.org/10.1007/7854_2015_402

Singer, T., \& Lamm, C. (2009). The social neuroscience of empathy. Annals of the New York Academy of Sciences, 1156, 81-96. https://doi.org/10.1111/j.1749-6632.2009.04418.x

Smith, S. M., Nichols, T. E., Vidaurre, D., Winkler, A. M., Behrens, T. E., Glasser, M. F., Ugurbil, K., Barch, D. M., Van Essen, D. C., \& Miller, K. L. (2015). A positive-negative mode of population covariation links brain connectivity, demographics and behavior. Nature Neuroscience, 18, 1565-1567. https://doi.org/10.1038/nn. 4125

Snyder, M. (1974). Self-monitoring of expressive behavior. Journal of Personality and Social Psychology, 30, 526-537. https://doi.org/ 10.1037/h0037039

Stratton, T. D., Elam, C. L., Murphy-Spencer, A. E., \& Quinlivan, S. L. (2005). Emotional intelligence and clinical skills: Preliminary results from a comprehensive clinical performance examination. Academic Medicine, 80, S34-S37.

Subramanian, Ł, Sękowski, M., \& Żemojtel-Piotrowska, M. (2020). Behavioral Inhibition System (BIS), Behavioral Activation System (BAS), and grandiose facets of narcissism. Current Psychology, 15, 1-7. https://doi.org/10.1007/s12144-020-00927-6

Taber, K. S. (2018). The use of Cronbach's alpha when developing and reporting research instruments in science education. Research in Science Education, 48, 1273-1296. https://doi.org/10.1007/ s11165-016-9602-2 
Takahashi, Y., Yamagata, S., Kijima, N., Shigemasu, K., Ono, Y., \& Ando, J. (2007). Gray's temperament model: Development of Japanese version of BIS/BAS scales and a behavior genetic investigation using the twin method. Japanese Journal of Personality, 15, 276-289.

Tangney, J. P., Baumeister, R. F., \& Boone, A. L. (2004). High selfcontrol predicts good adjustment, less pathology, better grades, and interpersonal success. Journal of Personality, 72, 271-322. https://doi.org/10.1111/j.0022-3506.2004.00263.x

Torrubia, R., Avila, C., Moltó, J., \& Caseras, X. (2001). The Sensitivity to Punishment and Sensitivity to Reward Questionnaire (SPSRQ) as a measure of Gray's anxiety and impulsivity dimensions. Personality and Individual Differences, 31, 837-862. https://doi.org/ 10.1016/S0191-8869(00)00183-5

Tusche, A., Böckler, A., Kanske, P., Trautwein, F. M., \& Singer, T. (2016). Decoding the charitable brain: Empathy, perspective taking, and attention shifts differentially predict altruistic giving. Journal of Neuroscience, 36, 4719-4732. https://doi.org/10.1523/ JNEUROSCI.3392-15.2016

Tzourio-Mazoyer, N., Landeau, B., Papathanassiou, D., Crivello, F., Etard, O., Delcroix, N., Mazoyer, B., \& Joliot, M. (2002). Automated anatomical labeling of activations in SPM using a macroscopic anatomical parcellation of the MNI MRI single-subject brain. NeuroImage, 15, 273-289. https://doi.org/10.1006/nimg. 2001.0978

Van Griethuijsen, R. A., van Eijck, M. W., Haste, H., den Brok, P. J., Skinner, N. C., Mansour, N., Gencer, A. S., \& BouJaoude, S. (2015). Global patterns in students' views of science and interest in science. Research in Science Education, 45, 581-603. https:// doi.org/10.1007/s11165-014-9438-6

Voigt, D. C., Dillard, J. P., Braddock, K. H., Anderson, J. W., Sopory, P., \& Stephenson, M. T. (1994). BIS/BAS scales and their relationship to risky health behaviours. Personality and Individual Differences, 47, 89-93. https://doi.org/10.1016/j.paid.2009.02.003

Volkow, N. D., Wang, G. J., Fowler, J. S., Tomasi, D., \& Telang, F. (2011). Addiction: Beyond dopamine reward circuitry. Proceedings of the National Academy of Sciences, 108, 15037-15042. https://doi.org/10.1073/pnas.1010654108

Watanabe, K., Kakeda, S., Nemoto, K., Onoda, K., Yamaguchi, S., Kobayashi, S., \& Yamakawa, Y. (2021). Grey-matter brain healthcare quotient and cognitive function: A large cohort study of an MRI brain screening system in Japan. Cortex, 145, 97-104. https://doi.org/10.1016/j.cortex.2021.09.009

Watson, E. M., Loveless, J. P., Stephenson, A. J., Bickel, K. L., Lehockey, K. A., \& Everhart, E. D. (2016). The relationship between anger, frontal asymmetry and the BIS/BAS subscales. Journal of Nature and Science, 2, e264.

Włodarska, K. A., Zyskowska, E., Terebus, M. K., \& Rogoza, R. (2019). The dark triad and BIS/BAS: A meta-analysis. Current Psychology, 40, 1-9. https://doi.org/10.1007/s12144-019-00467-8

Yamaji, H., Gotoh, M., \& Yamakawa, Y. (2019). Experimental analysis of corporate wage negotiations based on the ultimatum game: A new approach using a combination of laboratory and fMRI experiments. Computational Economics, 53, 873-900. https://doi.org/ 10.1007/s10614-017-9769-2

Yang, J., Tian, X., Wei, D., Liu, H., Zhang, Q., Wang, K., Chen, Q., \& Qiu, J. (2016). Macro and micro structures in the dorsal anterior cingulate cortex contribute to individual differences in selfmonitoring. Brain Imaging and Behavior, 10, 477-485. https:// doi.org/10.1007/s11682-015-9398-0

Yu, H., Jiang, S., \& Land, K. C. (2015). Multicollinearity in hierarchical linear models. Social Science Research, 53, 118-136. https:// doi.org/10.1016/j.ssresearch.2015.04.008

Zaccaro, S. J., Foti, R. J., \& Kenny, D. A. (1991). Self-monitoring and trait-based variance in leadership: An investigation of leader flexibility across multiple group situations. Journal of Applied Psychology, 76, 308-315. https://doi.org/10.1037/0021-9010. 76.2.308

Zhang, H., Lee, Z. X., White, T., \& Qiu, A. (2020). Parental and social factors in relation to child psychopathology, behavior, and cognitive function. Translational Psychiatry, 10, 1-9. https://doi.org/ 10.1038/s41398-020-0761-6

Zorza, J. P., Marino, J., de Lemus, S., \& Mesas, A. A. (2013). Academic performance and social competence of adolescents: Predictions based on effortful control and empathy. The Spanish Journal of Psychology, 16, e87. https://doi.org/10.1017/sjp.2013.87

Publisher's Note Springer Nature remains neutral with regard to jurisdictional claims in published maps and institutional affiliations. 